\title{
Incidence and Causes of Wastage of Blood \& Blood Components in a Blood Bank of Tertiary Care Hospital: A Retrospective Study
}

\author{
Kaur, Puneet ${ }^{1}$, Kaur, Rupinder ${ }^{2}$, Masih, Victor ${ }^{3}$, Jindal, Aikaj ${ }^{4}$ \\ ${ }^{1,2,3} \mathrm{MD}$ - Pathology, ${ }^{4} \mathrm{MD}$ - Transfusion Medicine \\ ${ }^{1,2,3}$ Department of Pathology, Christian Medical College and Hospital, Ludhiana \\ ${ }^{4}$ Department of Transfusion Medicine, Christian Medical College and Hospital, Ludhiana
}

\begin{abstract}
Abtract
Context:There is always a dearth of blood available for transfusion which can be reduced with more efficient utilization of blood or blood components

Aims:This study was aimed at finding reasons for discarding blood or blood components and to develop plans to reduce wastage

Materials and Methods:This was a retrospective observational study in blood bank unit of tertiary care hospital and included data from records for one year $\left(1^{\text {st }}\right.$ Jan 2014 to $31^{\text {st }}$ Dec 2014). Majority of blood donations were subjected to blood components processing. Reason for discarding blood or blood components was observed and results were analysed.

Results:Total 11923 blood bags were collected, 11804 were subjected to component preparation. Overall discard rate of whole blood and components was 5.8\%. Most common reason for discard was TTI $(74.2 \%)$, of which HCV formed the majority. Non-utilization due to expiry (17.1\%), blood sent for quality control(3.9\%) and other causes(leakage, contamination, DCT positivity and no available segment for cross match) constituted $4.8 \%$ of the discard rate.

Conclusions:Proper utilization of blood is needed with ideally zero percentage wastage. Most common reason for discard of blood/blood products in our study was seropositivity, followed by non-utilization of blood/blood products beyond expiry date. Proper screening of donors, detailed history, issuing blood/components based on FIFO (First in First out) policy and regular audit by hospital transfusion committee will help to reduce wastage.
\end{abstract}

Keywords:Blood Donation, Wastage of blood, Blood components

\section{Introduction}

Transfusion of safe blood and blood products are an integral part of patient management. ${ }^{[1]}$ Human blood till date has no substitute, hence each unit of blood is precious and should be used appropriately. ${ }^{[2]}$ There is always a gap between demand and supply of blood which can be reduced either by increasing the level of resources used in production of blood / blood components or by using available resources more efficiently. ${ }^{[3]} \mathrm{The}$ aim of the current study was to find the reasons for discarding of blood / blood components and develop plans to optimize utilization.

\section{Method}

This was a retrospective observational study carried out in blood bank unit of a tertiary care hospital data collected for period of one year from $1^{\text {st }}$ Jan 2014 to $31^{\text {st }}$ Dec 2014. The study included blood donations collected from both voluntary and replacement donors. Majority of blood collected was subjected to formation of components - two products [packed red blood cells (PRBC), fresh frozen plasma (FFP)] or three products [PRBC, FFP and random donor platelets (RDP)] as per the demand. Only 1\% of the donations were used as whole blood. The data was collected from the records available in blood bank. The study looked at various reasons for discarding blood (including whole blood) and blood components; namely transfusion transmitted infections (TTI), outdated / expired bags, leakage / breakage, bags send for quality control, bags showing discoloration due to RBC contamination for FFP and RDP, DCT positive PRBC's, red cell bags with no segment left for further cross match due repeated cross matching.

\section{Results}

A total of 11923 blood bags were collected in the study period of which 11594 (97.2\%) donors were males and $329(2.8 \%)$ were females. Of the total bags, 11804 (99\%) were made into 26554 blood components and 119 whole blood. 
Total 1557 units of blood / blood components were discarded with an overall discard rate of whole blood and blood components of 5.8\%. However discard rate of whole blood was much higher $(21.9 \%)$ when compared with other components. (Table 1)

Sero-positivity for TTI was the major cause of discarding blood with hepatitis C (HCV) being the commonest TTI (Table 2).

Total infection due to TTI was 1155 with $74.2 \%$ blood discarded due to TTI. 13 donors had dual infections, out of which 7 were quadruple bags and 6 were double bags. This was followed by non-utilization due to expiry $(17.1 \%)$, followed by blood sent for quality control (3.9\%) and various other causes (leakage, contamination, DCT positivity and no segment available for cross match) constituted $4.8 \%$ of the discard rate. (Table 3)The discard rate of platelets in the present study was $12.0 \%$ and main reason of discard of platelets in our study was expiry due to short shelf life (5days). The main reason of overall discard of whole blood and components in the present study was due to sero-positivity due to TTI (74.2\%), with commonest TTI detected being hepatitis C $(39.7 \%)$.

\section{Discussion}

Self-audit of blood and blood components discarded over a period of time provides us insight into avoidable and non-avoidable reasons of discard. It guides us to plan various alterations and corrections to reduce the wastage. Discard due to sero-positivity can be reduced by $100 \%$ voluntary donation and strict donor selection criteria.

Percentage of discarded whole blood and components in the present study was $5.8 \%$ which was less as compared to Roy et al ${ }^{[3]}(7.49 \%)$; but slightly higher as compared to Morish et al ${ }^{[1]}(2.3 \%)$ and Thakare et al ${ }^{[4]}$ $(3.58 \%)$.

Whole blood showed highest discard rate of $21.9 \%$ due to non-utilization in our study but it was less as compared to study done Roy et al ${ }^{[3]}$ where the discard rate of whole blood was $66.67 \%$. In the present study discard rate of whole blood was high because of establishment of component therapy in our institute. Whole blood was made only on demand (exchange transfusion, microvascular surgery), and was discarded if not utilized by that particular team.

PRBC had discard rate of $5.2 \%$ in our study which was comparable to other studies where it ranged from $2-4.49 \%{ }^{[3,5,6]}$ The main reason of discard of PRBC in our study and all the above studies was TTI.

Discard rate of FFP was $4.7 \%$ with TTI being the main reason of its wastage $(91.3 \%)$ followed by leakage $(7.2 \%)$ and RBC contamination $(1.5 \%)$. This was comparable to study done by Kumar et al ${ }^{[6]}(7.25 \%)$. In another study done by Morish et al ${ }^{[1]}$ discard rate of FFP due to leakage was much higher (43\%) as compared to present study. Reason for leakage of plasma in our study was mishandling of blood bags during collection, storage and manufacturing,

The discard rate of platelets in the present study was $12.0 \%$ which is much less as observed by various other studies where it ranged from $26.2 \%$ to $43.6 \%{ }^{[5,6]}$ The main reason of discard of platelets in our study was expiry due to short shelf life (5days).

The main reason of overall discard of whole blood and components in the present study was due to sero-positivity due to TTI $(74.2 \%)$. In other studies also TTI was the main reason for discarding blood/ blood components. However in most of the studies hepatitis B had the highest incidence among TTI's (32.5\% to $69.8 \%)^{[4,6]}$ whereas in our study the commonest TTI detected was hepatitis C $(39.7 \%)$.

\section{Conclusion}

Blood is a very previous resource which needs to be utilized appropriately with ideally zero percentage wastage. The most common reason for discard of blood or blood products in our study was sero-positivity and non-utilization of blood beyond expiry date. Arranging the near expiry blood and components in front shelves of storage areas of blood banks (refrigerators and platelet agitators) and following FIFO (First in First out) policy will help in reducing wastage. Regular audit by hospital transfusion committee would also ensure reducing wastage. Currently there are only few indications for the use of whole blood, so its preparation should be strictly according to demand to minimize wastage. Proper screening of donor should be done with detailed history to avoid wastage due to TTI's at the front desk itself as blood safety still depends highly on open and honest answering of screening questions.

\section{References}

[1]. Morish M, AyobY, Naim N, Salman H, Muhamad NA and Yusoff NM. Quality indicators for discarding blood in National Blood center, Kuala Lumpur. Asian J TransfusSci2012;6:19-23.

[2]. An action plan for blood Safety. New Delhi: National AIDS Control Organization, Ministry of Health and Family Welfare Government of India, MOHFW; 2003.

[3]. Roy AD and Pal A. Evaluation of 'Wastage Rate' of Blood and Components - An Important Quality Indicator in Blood Banks. BJMMR 2015;8(4):348-52. 
[4]. Thakare MM, Dixit JV andGoel NK. Reasons for discarding blood from blood bank of government medical college, Aurangabad. Asian J TransfusSci 2011;5:59-60.

[5]. Bobde V, Parate S and Kumbhalkar D. Analysis of discard of whole blood and blood components in government hospital blood bank in central India. J of Evidence Based Med \& Healthcare 2015;2:1215-20.

[6]. Kumar A, Sharma S, Ingole N, Gangane N. Analysis of reasons for discarding blood and blood components in a blood bank of tertiary care hospital in central India: A prospective study. Int J Med Public Health 2014;4(1):72-4.

\section{TABLES}

Table 1

\begin{tabular}{|c|c|c|c|}
\hline Hood Component & $\begin{array}{l}\text { No: of Camponents } 8 \\
\text { Whole Blood prepared }\end{array}$ & No. of unit discarded & Discarded Rate* \\
\hline PRIAC: & 11364 & 585 & $5.2 \%$ \\
\hline$F P$ & 11288 & 530 & $4.7 \%$ \\
\hline RDP & 3462 & 414 & $12.0 \%$ \\
\hline Sop & 440 & 02 & $0.5 \%$ \\
\hline WB & 119 & 26 & $21.9 \%$ \\
\hline Total & 26673 & 1557 & $5.8 \%$ \\
\hline
\end{tabular}

Table 1 - Analysis of discarded units of whole blood \&blood components against total prepared * Discarded rate $=$ Number of units discarded $(\mathrm{WB}, \mathrm{PRBC}, \mathrm{PC}, \mathrm{FFP}, \mathrm{SDP}) /$ Number of units prepared (WB, PRBC, RDP, FFP, SDP) $\times 100$

\section{Table 2}

\begin{tabular}{|c|c|c|c|c|c|}
\hline Total discarded & HIV & HBSAE & HCV & VDRL & MPP \\
\hline WB & 0 & 0 & 0 & 0 & 01 \\
\hline BABC & 40 & 90 & 196 & 158 & 0 \\
\hline FFP & 40 & 90 & 196 & 158 & 0 \\
\hline RDP & 18 & 43 & 66 & 59 & 0 \\
\hline Total & 98 & 223 & 458 & 375 & 01 \\
\hline
\end{tabular}

Table 2 - Analysis of whole blood /components discarded due to seropositivity / Infections WB (whole blood) PRBC (Packed Red Blood Cells), FFP (Fresh Frozen Plasma) RDP (Random Donor Plasma) SDP (Single Donor Platelet)

Table 3

\begin{tabular}{|c|c|c|c|c|c|c|c|c|}
\hline Cangenes & $m$ & costentre & $\begin{array}{l}\text { duaury } \\
\text { conmines }\end{array}$ & ueware & covetavedianom & 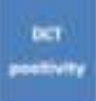 & $\frac{\mathrm{N}^{2}}{\mathrm{Nex}}$ & nate \\
\hline wo & $t$ & 4 & 10 & 3 & 4 & 4 & 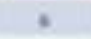 & 28 \\
\hline whes: & sad & s4. & 30 & u & 4 & 0 & 0 & 395 \\
\hline mir & iad & 6 & e & 4 & 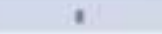 & 0 & e. & 530 \\
\hline ner & 196 & 201 & u & 1 & 3 & 0 & 0 & 24) \\
\hline sor & & er & 0 & e & s. & 0 & 0 & $\boldsymbol{A}$ \\
\hline \multirow[t]{2}{*}{ Tetal } & Its & 236 & 61. & s) & us & ea & os & 1857 \\
\hline & $742 \mathrm{v}$ & 17) & s9s & \multicolumn{4}{|c|}{ in } & 5ss \\
\hline
\end{tabular}

Table 3 - Analysis of reasons of discarded whole blood and components 